\title{
La mujer víctima: a propósito de la ley para prevenir, sancionar y erradicar la violencia contra las mujeres y los integrantes del grupo familiar
}

\section{The Victim Woman: Regarding the Law to Prevent, Sanction and Eradicate Violence against Women and the Members of the Family Group}

Ricardo Alfredo Díaz Bazán* http://dx.doi.org/10.21503/lex.v14i17.938

* Abogado por la Universidad Nacional Mayor de San Marcos, magíster en Administración, magíster en Derecho Civil, doctor en Derecho, docente universitario de pregrado y postgrado en diferentes universidades del Perú, conferencista nacional e internacional. Decano de la Facultad de Derecho y Ciencia Política de la Universidad Alas Peruanas. E-mail: r_diaz@uap.edu.pe

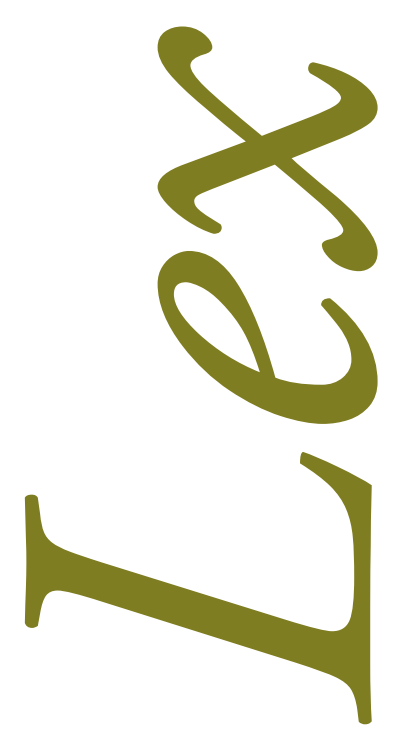




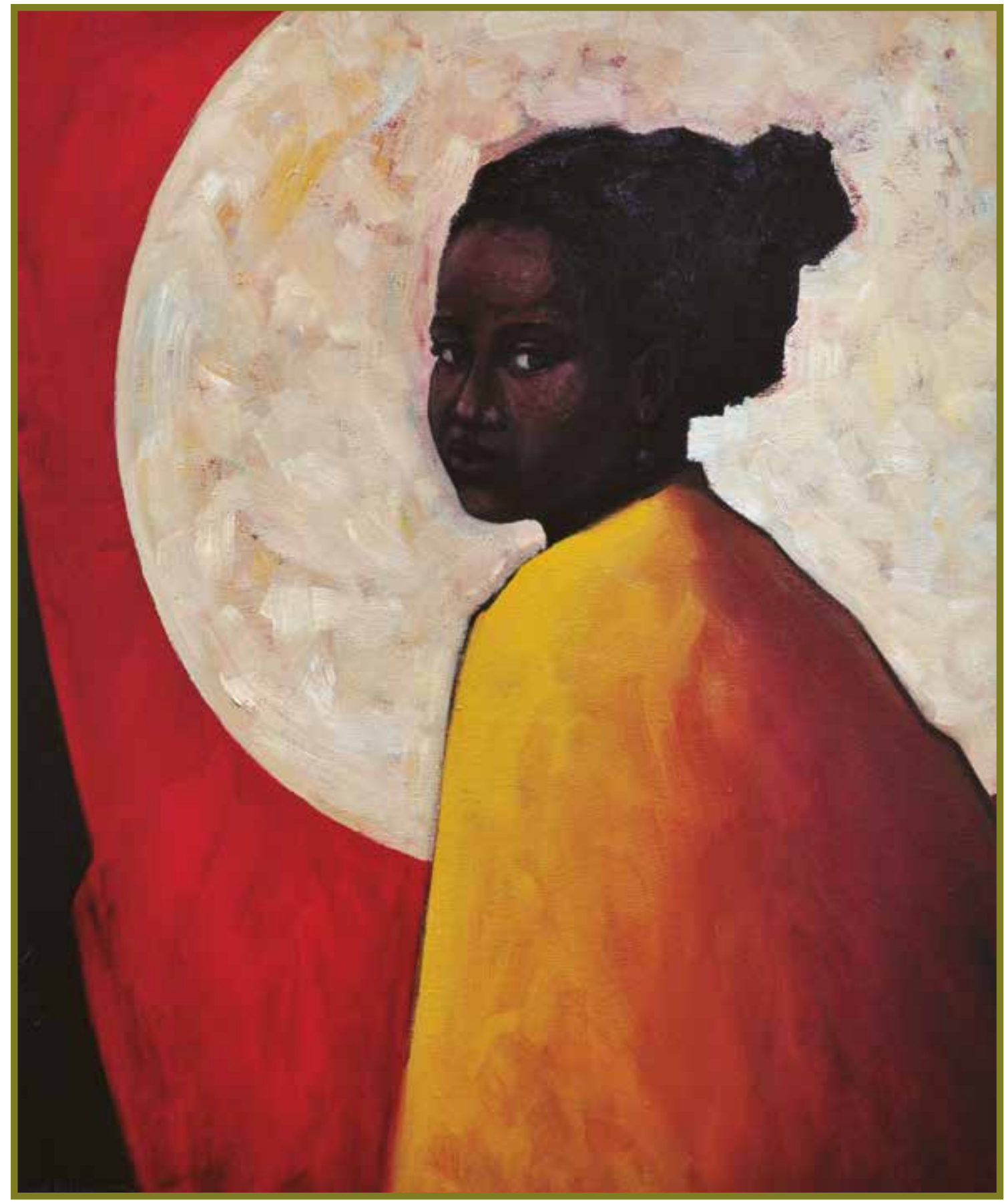

Niña Luna $(70 \mathrm{~cm}$ x $90 \mathrm{~cm})$. Diego Alcalde Taboada. 


\section{RESUMEN}

El presente artículo tiene como objetivo analizar los derechos o garantías de la mujer víctima previstos en la Ley $N^{\circ} 30364$ Ley para Prevenir, Sancionar y Erradicar la Violencia contra las Mujeres y los Integrantes del Grupo Familiar, norma que deroga la Ley de Protección Frente a la Violencia Familiar.

Palabras clave: victimología, prevenir, sancionar, erradicar la violencia contra la mujer.

\section{ABSTRACT}

This paper has as aim to analyze women's rights and guaranties victim laid down in the Law 30354, Law to Prevent, Sanction and Eradicate violence against Women and Members of the Family Group, law which abolishes the Law of Protection against Family Violence.

Key words: victimiology, prevent, sanction, eradicate violence against women. 


\section{INTRODUCCIÓN}

El 23 de noviembre del 2015, fue publicada la Ley No 30364, Ley para Prevenir, Sancionar y Erradicar la Violencia contra las Mujeres y los Integrantes del Grupo Familiar, norma que no solo deroga la Ley 26260 Ley de Protección frente a la Violencia Familiar" sino que también modifica los artículos 45, 121-A, 121-B, 122, 337 y 338 del Código Penal, incorpora los artículos 46-E y 124-B al Código Penal, modifica el artículo 242 del Código Procesal Penal promulgado por el Decreto Legislativo 957 y. por último, modifica el artículo 667 Código Civil.

La norma en comento es un gran avance para nuestro país, ya que por primera vez sanciona la violencia contra la mujer por razones de género. Nuestra derogada Ley de Protección frente a la Violencia Familiar, en su artículo segundo ${ }^{1}$ claramente establecía que la protección de la violencia era solo cuando la víctima era del entorno familiar, restringiéndose sus derechos por su condición de mujer.

La violencia de género es un fenómeno que existe desde el origen mismo de la sociedad patriarcal, y así lo demuestran los datos ofrecidos por distintos estudiosos y organismos, pero que no ha sido conceptualizado como tal hasta una época reciente. ${ }^{2}$

Han existido intentos legislativos en protección a la víctima femenina. La derogada Ley de Protección frente a la Violencia Familiar no ha cumplido con sus objetivos trazados. Por eso, en el presente artículo académico comentamos por qué consideramos que esta nueva Ley significa una verdadera protección a la mujer víctima y a otros integrantes del grupo familiar, y a su vez esbozamos puntos importantes que no fueron tomados en cuenta y cuya indebida aplicación puede causar una doble victimización a la verdadera mujer víctima.

\footnotetext{
Artículo 2 de la Ley $N^{\circ}$ 26260. "A los efectos de la presente ley, se entenderá por violencia familiar cualquier acción u omisión que cause daño físico o psicológico, maltrato sin lesión, inclusive la amenaza o coacción graves que se produzcan entre: a. conyugues, b. convivientes, c. ascendientes, d. descendientes, e. parientes colaterales hasta el cuarto grado de consanguinidad y segundo de afinidad, f. o quienes habitan en el mismo lugar, siempre que no medien relaciones contractuales o laborales.

2 María Concepción Gorjon Barranco, La tipificación del género en el ámbito penal. Una revisión crítica a la regulación actual (España: IUSTEL, Universidad de Salamanca, 2012), 29.
} 


\section{RECORRIENDO LA HISTORIA: LA MUJER DESDE LA VICTIMOLOGÍA}

El término de victimización fue utilizado desde las primeras épocas de la historia, pero en la cultura griega adquirió una connotación especial a partir de sus representaciones mitológicas y el lenguaje dionisiaco empleado para plasmar la realidad, sus percepciones frente al mundo y los fenómenos naturales acaecidos, como lo sucedido con el dios Apolo y su hermana Artemisa, quien era la diosa de la caza y de las fieras, y que al igual que su gemelo victimizaba a animales, seres indefensos y mujeres que estuviesen a punto de traer una nueva vida. ${ }^{3}$

En la edad media y en la colonia el Feudal era a quien se le concedía el privilegio de estar con la mujer virgen por ser el Jefe encargado de dirigir este grupo de individuos, pero esto demuestra la victimización de la mujer en los ritos religiosos de agravios, laceraciones, extirpaciones, incisiones ocasionadas en sus genitales y otras partes del cuerpo, de una forma $\mathrm{u}$ otra ha sido predispuesta a vulneraciones e incluso de los medios masivos de comunicación $\mathrm{n}^{4}$.

Las leyes de Roma, contenidas especialmente en las Doce Tablas, mantienen el principio taliónico, pero agregan "a no ser que la víctima lo determine de otra manera, de acuerdo con el malhechor"; el derecho a la venganza lo tenía la víctima, pues su ejercicio quedaba a su propia discreción. Así por ejemplo, la composición por un hombre muerto era mucho mayor a la de una mujer. En un principio, en el sistema de composiciones la mujer no tenía derecho a cobrar, pues se le consideraba incapaz de ejercitar la venganza familiar. Luego se le otorgó derechos en caso de que faltaran herederos varones. ${ }^{5}$ Una vez más vemos relegada los derechos de la mujer por su condición de tal.

Las teorías tradicionales de la criminalidad aludían a los hombres como los principales transgresores de las leyes, debido a la influencia de este en los distintos ámbitos de la vida, su proximidad con el marco legal y la preponderancia de tabúes y creencias enmarcados en la sociedad. No obstante, doctrinantes como Lombroso o Sigmund Freud analizaban la participación de la mujer en el crimen, explicándolo desde su comportamiento con los otros individuos y la incapacidad de ser victimaria por su fisonomía, el complejo de castración y posteriormente el complejo de Edipo. ${ }^{6}$

Es así que desde la creación del mundo la mujer ha estado predispuesta para ser en primer lugar víctima del sexo opuesto por su condición de tal. A eso se han sumado sendas investigaciones que con el transcurso de los años han pretendido dar a la mujer una protección

\footnotetext{
"Estudios de Derecho. Un acercamiento teórico a la mujer víctima-victimaria”, proyecto de investigación publicado por la Universidad de Antioquia, 155, volumen LXX, segunda época (junio de 2013): 247.

María Concepción Gorjon Barranco, La tipificación..., 35.

5 Elky Villegas Paiva, El agraviado y la reparación civil en el nuevo Código Procesal Penal, primera edición (Lima: Editorial Gaceta Jurídica S.A.), 34.

6 "Estudios de Derecho. Un acercamiento teórico a la mujer víctima-victimaria”..., 244-245.
} 
frente al agresor, pero en ese intento de protección se han cometido errores en la norma que han dificultado su aplicación, que a mi modesto entender se podría entender como una doble victimización a la verdadera mujer víctima.

En el Perú se vivió en la década de 1980 y 2000 una época de violencia a la cual se le llamaba "conflicto armado interno", el que fue iniciado por un grupo interno terrorista llamado Partido Comunista del Perú - Sendero Luminoso, el cual sostuvo enfrentamientos armados con las fuerzas armadas y policiales del Estado Peruano y que ocasionaron miles de pérdidas humanas y materiales, así como una masiva violación de derechos humanos y materiales. ${ }^{7}$ Recuérdese que las primeras víctimas fueron los campesinos y campesinas de los pueblos alejados de nuestro querido Perú, que por estar alejados tenían poca protección de las fuerzas del orden.

\section{LA VIOLENCIA}

Como punto de partida definamos a la violencia. Según Calabrese, "la violencia y la agresión son dos caras de la misma moneda que tradicionalmente ha sido aceptada como mecanismo de control por los individuos que han ostentado el papel hegemónico dentro del grupo social que de uno u otro modo se han visto justificados y, por lo tanto, legitimados en el ejercicios de esa violencia y de ese poder arbitrario. Por su parte, Velasco Gamboa se pregunta qué es la violencia más allá de la terminología y de la doctrina, y la respuesta que halla es la siguiente: "Es un mal de las mismas dimensiones que el cáncer o el SIDA: que corrompe y destruye a las personas y sociedad de manera lenta y gradual pero efectivo. $Y$ es un mal más antiguo que los mencionados". ${ }^{8}$

De la rugosa mano de una herencia psicológica inconsciente llega el delito a nuestros días, a nuestras actitudes habituales, a nuestro pensamiento, a los actos fallidos que emitimos y que lo proclaman. Claro está que una cosa es el delito y otra llegar a ser delincuente. ${ }^{9}$

La violencia no solo deja huella en la vida, sino también dirige el destino de nuestra sociedad. Si la violencia ha sido muy grave, tendremos una sociedad retrasada, dolida, sin aspiración ni proyección. Con un país sin violencia, tendremos decisiones más acertadas.

Al hilo de esta argumentación que pone en relación la violencia y la agresión, el mismo CGP ${ }^{10}$ afirma que "conceptualmente la violencia se presenta como un estadio más avanzado

7 Luis Andrés Roel Alva, "El derecho a la reparación económica del Programa Integral de Reparación del Estado", Gaceta Constitucional, 69 (setiembre de 2013): 313-314.

8 María Concepción Gorjon Barranco, La tipificación..., 35.

9 Elías Neuman, El rol de la víctima en los delitos convencionales (Buenos Aires: Universidad de Buenos Aires, 1984$), 17$.

10 Informe al Anteproyecto de la Ley Orgánica integral de medidas contra la violencia ejercida sobre la mujer, del Consejo General del Poder Judicial de 21 de junio del 2004, Madrid. 
de la agresividad. No hay violencia en sentido técnico, por una agresión aislada, esporádica, sino que esa agresión debe producirse en un contexto de sometimiento de la víctima. El agresor — sujeto dominante- se mueve en un ambiente en el cual la víctima se encuentra subordinada. Ello se produce paulatinamente en un contexto de continua (...). En este sentido puede hablarse de relaciones de dominación". Este es un razonamiento clave que dará la pauta respecto de las características propias del género. ${ }^{11}$

Encuadramos en ello a la violencia contra la mujer, sexo débil olvidado por muchos años, con una desprotección normativa y un intento de protección mal regulado en nuestro país.

\section{VIOLENCIA Y FAMILIA: VIOLENCIA FAMILIAR E INTRAFAMILIAR}

\section{Violencia doméstica}

También se han llegado a utilizar indistintamente los términos de violencia familiar y doméstica, ¿pero realmente son lo mismo? Pareciera que no. Si tomamos en cuenta la definición de violencia acabada de poner de manifiesto, nos llama la atención que en México, la NOM-190-SSA1 definiera la violencia familiar como "un acto u omisión único o repetitivo, cometido por un miembro de la familia, en relación de poder — en función del sexo, la edad o la condición física -, en contra de otro u otros integrantes de la misma, sin importar el espacio físico donde ocurra el maltrato físico, psicológico, sexual o abandono", es decir, definiendo como violencia no solo los actos repetitivos, sino también los que suponen la comisión de un solo acto violento, y sobre todo que no se limita al espacio doméstico. ${ }^{12}$

Rosillo Sánchez refiere ${ }^{13}$ que el artículo $1^{\circ}$ de la Constitución Política del Perú establece que "la persona humana es el fin supremo del Estado"; en consecuencia, con este principio se debe interpretar que es posible establecer asistencia y protección a favor de las víctimas femeninas.

A nivel europeo, la Recomendación $\mathrm{N}^{\circ} \mathrm{R}$ (85) 4 del Comité de Ministros del Consejo de Europa a los Estados miembros sobre la violencia dentro de la familia (adoptada por el Comité de Ministros el 26 de marzo de 1985, en la 382 reunión de los Delegados de los Ministros) define la violencia en la familia como "todo acto u omisión que atente contra la vida, la integridad física o psíquica o la libertad de una persona, o que ponga gravemente en peligro el desarrollo de su personalidad, considerando que tal violencia afecta en particular, aunque en condiciones diferentes, por una parte, a los niños y por otra, a las mujeres". ${ }^{14}$

11 María Concepción Gorjon Barranco, La tipificación..., 35.

12 María Concepción Gorjon Barranco, La tipificación..., 36.

13 Omar Levi Rosillo Sánchez, "La víctima y el testigo en el Código Procesal Penal de 2004", Revista de Actualidad Jurídica, 197 (2010):133.

14 María Concepción Gorjon Barranco, La tipificación..., 36. 
Hernández Ehlers simplifica y alude a que algunos teorías definen a la violencia intrafamiliar desde el punto de vista de la "agresividad instintiva", y otras, sin embargo, la definen como un problema multicausal, en el que es necesario analizar diversos factores de tipo cultural, económico, legal y político, que en cada caso serán considerados como los responsables de la violencia. A partir de la definición de la violencia familiar intrafamiliar se observa que la manifestación de la violencia está ligada al ejercicio del poder, al uso de la fuerza, ya sea física, psicológica, sexual, económica o política. A estas condiciones estructurales de la violencia intrafamiliar se suma una condición externa de consenso social, mantenida por sectores tradicionales, que otorgan legitimidad al agresor y dejan sin recursos a la víctima. Es importante, por tanto, distinguir las corrientes que ubican este tipo de violencia en características individuales del autor y aquellas que relacionan con causas de tipo estructural. En cualquier caso, la violencia intrafamiliar es considerada entonces como una de las costumbres y prácticas más graves para el tejido familiar por su carácter destructivo y porque pone en desventaja a la mujer. Benítez Jiménez acoge la definición de violencia intrafamiliar dada por el Consejo de Europa como "toda acción u omisión cometida en el seno de la familia por uno de sus miembros, que menoscaba la vida o la integridad física o psicológica, o incluso la libertad de otro de los miembros de la misma familia y que causa un serio daño al desarrollo de su personalidad". ${ }^{15}$ Consideramos nosotros que la violencia intrafamiliar tiene múltiples causas; por ello, se deben analizar sus factores de tipo cultural, económico, legal y político, que en cada caso serán considerados como los responsables de la violencia. Consideramos también que el factor cultural es el más importante.

\section{TENDENCIAS CRIMINOLÓGICAS DESDE EL FEMINISMO}

La ciencia de la criminología tiene su auge en el siglo XIX con Lombroso, quien buscó las causas del delito en la persona del delincuente. El patriarcado se ha encargado, como hemos visto, de recluir a las mujeres en el ámbito privado, y su no aparición en el ámbito público ha influido en su no aparición pública tampoco como delincuente. ${ }^{16}$ Consecuentemente, se ha victimizado a la misma por su condición de mujer.

Desde la perspectiva feminista, en la criminológica podemos distinguir tres etapas a lo largo del s. XX. La primera de ellas coincide en el marco de la criminología tradicional en la que se utilizó una visión machista sobre la mujer delincuente que fortalecía los estereotipos de sumisión, pasividad e inferioridad. La segunda tiene su auge en los años setenta y ya se hace referencia propiamente a una criminología feminista, pero no es hasta la tercera de las etapas (años noventa), cuando se incorpora a esta ciencia la perspectiva de género. ${ }^{17}$

15 María Concepción Gorjon Barranco, La tipificación..., 35.

16 María Concepción Gorjon Barranco, La tipificación..., 49.

17 María Concepción Gorjon Barranco, La tipificación..., 50. 
Así, el propio Barata afirma que en los años 70 del pasado siglo es cuando la cuestión feminista se convierte en una cuestión criminal y se desarrolla la victimología, que, como hemos visto, desemboca en el estudio de los casos de violencia, de denuncias, etc.

En la criminología crítica destacamos el aporte de Larrauri y el cuestionamiento de la efectividad de la utilización del Derecho Penal como instrumento que dé solución al problema de la violencia de género ${ }^{18}$. En busca de la solución al problema de la violencia de género, han respondido en la Ley N ${ }^{\circ} 30364$ "Ley para Prevenir, Sancionar y Erradicar la Violencia contra las Mujeres y los Integrantes del Grupo Familiar".

En la postmodernidad del Derecho Penal se han retomado ciertos enclaves que recuerdan al pasado y se habla de "nuevo paradigma actuarial, donde el control ya no busca proyectarse sobre individuos concretos, sino que se expande por el tejido social incidiendo sobre categorías de sujetos que se perciben como un riesgo". Como establece De Giori, al día de hoy la técnica de control del delito no responde tanto a indagar en las causas, sino al control preventivo del delito, y ello, apostilla el autor, se ha hecho a semejanza de las técnicas utilizadas por los procedimientos matemáticos aplicados a los seguros, es decir, que "desde el punto de vista de la lógica aseguradora, existen factores de riesgo distribuidos de forma causal en el ámbito de una colectividad, que solo pueden ser atribuidos directamente a individuos concretos en tanto que estos se inscriben en grupos determinables en base a un mayor o menor índice de riesgo. La estrategia aseguradora consiste ante todo en una operación de cuantificación probabilística del índice de riesgo existente que se realiza a través de valoraciones estadísticas", y esta es la estrategia que las políticas criminales han extrapolado al ámbito penal para controlar el delito. ${ }^{19}$

En lo que concierne al control del propio cuerpo de las mujeres a través de la creación de estereotipos o grupos de comportamiento, es decir, cómo el Derecho construye a las mujeres. El problema es cómo articular una estrategia feminista que represente al colectivo femenino en su conjunto contando con las características propias de cada mujer, la mujer (como idea patriarcal) o a las mujeres (término del que se ha servido el feminismo), siendo incluso la denominación "mujeres" bastante problemática, pues, "dar con una realidad absoluta localizada en el cuerpo de las mujeres, y en contra de la cual se puedan medir los excesos del patriarcado, se ha convertido en menos sostenible. El feminismo no representa a las mujeres, pues hay estrategias a partir de las cuales la mujer-mujeres son creadas", siendo una de ellas el Derecho, afirmación que podemos comprobar si valoramos el análisis de los delitos históricamente relacionados con las mujeres, como el adulterio, el infanticidio atenuado por deshonra, el aborto, etc. ${ }^{20}$ Enmarcándose escandalosamente en la mujer el adulterio, ya que no solo perdía a su familia y amigos, sino que se ganaba el repudio de la sociedad.

18 María Concepción Gorjon Barranco, La tipificación..., 50.

19 María Concepción Gorjon Barranco, La tipificación..., 51.

20 María Concepción Gorjon Barranco, La tipificación..., 52. 


\section{LA VÍCTIMA FEMENINA}

Respecto de la consideración de la víctima mujer, proponemos dos enfoques desde los que acercarnos a la situación concreta de maltrato: el primero sería el relativo a la propia terminología "víctima" y a las consecuencias derivadas de ello para las mujeres maltratadas, y el segundo enfoque se dirigiría a las propias medidas que han sido tomadas a nivel estatal, siendo muchas de ellas impuestas pese a la negativa de la propia mujer. ${ }^{21}$

Estamos de acuerdo en que lo que dota de sentido al concepto "violencia de género" como categoría sociológica es que la víctima sea mujer, es decir, que el sujeto pasivo sea mujer, pero cuidado con esto. En verdad, el término víctima puede reducir a un papel pasivo a las mujeres necesitadas únicamente de proclamar su inocencia. Según Peces-Barba, "la vulnerabilidad social de las víctimas supone que existe un desvalor añadido al simple y ya inherente a cualquier tipo de acción de maltrato, amenazas, coacciones. Cuando se atenta contra una mujer que se encuentra sometida a una situación de dominio cultural respecto a su agresor se está incurriendo en un plus de desvalor adicional respecto a la gravedad del hecho mismo, además de la fuerza física. A nadie se le ocurría considerar como inconstitucional la mayor penalidad del homicidio o asesinato del Rey, o de los miembros de la Familia Real”, justificando, por tanto, la mayor gravedad de estas situaciones en concreto porque los sujetos pasivos son más débiles. Pero hay que tener rigor a la hora de referirse a estas cuestiones, pues podemos caer en el paradigma de la victimización; es por eso que muchas feministas prefieren emplear el término "superviviente". En este sentido podemos ver que los términos víctima y superviviente se refieren a una misma situación, pero lo que varía es la manera de aproximarse a esa realidad, desde el lado positivo, que empodera, o desde el negativo, que victimiza aún más. El problema social y político de las mujeres se ha desplazado desde el concepto de opresión, que es el que en realidad denuncia una situación estructural, al de victimización, que se refiere a un daño individual, y precisamente este es el eje que no hemos querido perder de vista en este trabajo. Y ello se debe fundamentalmente a la simplificación que se ha hecho de la víctima, individualizada y dejando de lado el contexto general, "pues allí donde la noción de opresión hacía referencia a una entera biografía y a un contexto complejo de relaciones jerárquicas, incluyendo poder y desigualdades sociales y económicas, la noción de víctima tan solo evoca un acontecimiento puntual del que es responsable alguien con nombre y apellido, cuya responsabilidad es individual, propia”. ${ }^{22}$

En cuanto al papel de las "mujeres-víctimas", baste recordar que una de las premisas del Derecho Penal liberal, es que el "ius puniendi es del Estado, y no de particulares ofendidos ni perjudicados por los delitos, por lo que hay que evitar dinámicas procesales que puedan aventurar o tengan el peligro de reintroducir mecanismos propios de la respuesta privada

21 María Concepción Gorjon Barranco, La tipificación..., 329.

22 María Concepción Gorjon Barranco, La tipificación..., 331. 
frente al delito". Con carácter general venimos asistiendo en la actualidad a un papel predominante de la víctima en la esfera penal. Esas corrientes que reintroducen a la víctima en la resolución del conflicto se han denominado victimología y victimodogmática, y es por eso que desde hace años, el impulso de las corrientes victimológicas reclama un lugar para las víctimas. Pero el movimiento pendular en la materia que ahora nos ocupa ha ido demasiado lejos, "el modelo penal de la seguridad ciudadana tiene interés en socavar subprincipios tales como el monopolio estatal del ius puniendi, otorgando un protagonismo creciente a las demandas de las víctimas". En este ámbito también los lobbies de mujeres han buscado colocar las reivindicaciones de las víctimas de la violencia machista en un primer plano penal, por el que "el discurso de la víctima tiene especial reflejo en los medios de comunicación. La llamada opinión pública ocupa el lugar de la víctima del delito en tanto en cuanto es la posición más claramente delimitada y menos matizada, por lo que resulta más fácil identificarse con ella". ${ }^{23}$

Tal y como la corriente garantista temía, en realidad la modernización del Derecho Penal que surgió para criminalizar a los poderosos ha acabado por calar en conductas pertenecientes a la criminalidad tradicional, como es el caso de la violencia doméstica. ${ }^{24}$

En este sentido, la medida más problemática es "la decisión político-criminal de obligar a imponer en todo caso la pena de alejamiento cuando de violencia de género se trata, y encuentra su razón de ser precisamente en el desmedido protagonismo que en los últimos años vienen ocupando las víctimas en el sistema penal" (matizamos que son ciertos grupos de mujeres). Esta medida, en vez de fomentar el papel activo de las mujeres dentro de las redes sociales sigue perpetuándolas en el estado de incapacidad, de inferioridad, de vulnerabilidad, etc., cuando es mejor, a los fines que se pretenden, fomentar su papel activo, es decir, empoderar a las mujeres en sus relaciones sociales para acabar con el ciclo en el que en los últimos tiempos nos hemos sumido, por lo que sería interesante promover otro tipo de respuesta, que no sean las estrictamente penales, en la resolución de los problemas de las mujeres, ampliando el abanico con soluciones más eficaces y que conlleven una menor victimización. ${ }^{25}$

Por lo general, muchas de las mujeres maltratadas no solo son dependientes emocionalmente de sus parejas, sino que además lo son económicamente. De nada valen las campañas que animan a la mujer a denunciar si tras ello, estas deben volver a la casa compartida con su agresor. Es importante colocar a la mujer en una situación de poder para que pueda afrontar la situación fortalecida.

Por otra parte, en las investigaciones realizadas sobre la violencia de género, la catedrática de Derecho Penal María Luisa Maqueda, en la Universidad de Granada, afirmó que quizás

23 María Concepción Gorjon Barranco, La tipificación..., 331.

24 María Concepción Gorjon Barranco, La tipificación...., 332.

25 María Concepción Gorjon Barranco, La tipificación..., 334. 
uno de los grandes problemas de la sociedad es negarse a reconocer la violencia como parte de la realidad mundial y no una "cuestión biológica, ni doméstica sino de género", y no puede equipararse a la violencia doméstica porque esta va dirigida a cualquier miembro de la familia y no a los seres considerados más frágiles como la mujer y los niños, pues estos seres han sido analizados desde una mirada hegemónica donde lo relevante no es el sexo o a edad, la individualidad o colectividad de los actos agresivos cometidos, sino la discriminación histórica y la señalización cultural de unos valores subyacentes a ellos. En respuesta a esta inconformidad se han creado leyes, firmado convenios, tratados y acuerdos en búsqueda de la reivindicación de los derechos de la mujer, su anticipación en los diferentes campos, la visualización de las agresiones padecidas, el enfrentamiento a su continua tutorización, su incapacidad, sentimiento de culpa, angustia y por otra parte, la necesidad de su desinstrumentalización.

Hemos recorrido por la reacción mundial a la violencia de género, que en algunos países como exponemos no ha pasado de ser un intento normativo de desprotección a la mujervictima; que sin embargo la dación de la presente norma ha pretendido dar una verdadera protección a las víctimas de violencia contra las mujeres y los integrantes del grupo familiar.

LEY N 30364 "LEY PARA PREVENIR, SANCIONAR Y ERRADICAR LA VIOLENCIA CONTRA LAS MUJERES Y LOS INTEGRANTES DEL GRUPO FAMILIAR"

A continuación analizaremos los aciertos y desaciertos de la presente Ley $\mathrm{N}^{\circ} 30364$, que consideramos importante y sin duda es un gran avance en reconocimiento a la mujer víctima

La norma en comento cuenta con cuatro capítulos, la misma que comentaremos a continuación:

TITULO I: Disposiciones Sustantivas para la Prevención, Sanción y Erradicación de la Violencia contra las Mujeres y los Integrantes del Grupo Familiar:

Lo más resaltante del Capítulo I es el Objeto de la Ley, ${ }^{26}$ en la medida que amplía la protección a la mujer víctima de violencia de género, dado que su protección no es solo la protección de la violencia familiar contemplada en la derogada Ley de Violencia Familiar $N^{\circ} 26260$ (norma que en su artículo $2^{\circ}$ era específica en su protección, es decir, aquella

26 Artículo 1.- Objeto de la Ley.- La presente Ley tiene por objeto prevenir, erradicar y sancionar toda forma de violencia producida en el ámbito público o privado contra las mujeres por su condición de tales y contra los integrantes del grupo familiar, en especial cuando se encuentren en situación de vulnerabilidad por la edad o situación física, como las niñas, niños, adolescentes, personas adultas mayores y personas con discapacidad. Para tal efecto, establece mecanismos, medidas y políticas integrales de prevención, atención y protección de las víctimas así como la reparación del daño causado y dispone la persecución, sanción y reeducación de los agresores sentenciados con el fin de garantizar a las mujeres y al grupo familiar una vida libre de violencia asegurando el ejercicio pleno de sus derechos. 
violencia cometida por personas vinculadas familiarmente a la víctima, como eran los cónyuges, convivientes, exconvivientes, ascendientes, descendientes, parientes colaterales hasta el cuarto grado de consanguinidad y segundo de afinidad, quienes habitan en el mismo hogar, sin relación laboral o contractual, quienes hayan procreado hijos), sino que va más allá, recuérdese que la derogada ley limitaba el derecho a la mujer. Siendo muchas veces sujeto pasivo en el ámbito público y privado por su condición de mujer.

Es así que el ámbito de aplicación de la norma que contempla el artículo $4^{\circ}$ de la Ley $\mathrm{N}^{\circ} 30364^{27}$ es muy amplio, dejando atrás el concepto vetusto, ya que la norma en comento emplea una definición amplia contra las mujeres. ${ }^{28}$ Recuérdese que la fenecida ley de violencia familiar no ofrecía una protección amplia de los derechos de la mujer víctima. Más aún, amplía su definición de violencia contra los integrantes del grupo familiar. ${ }^{29}$

Es también importante precisar que la definición de violencia contra las mujeres deviene de que contempla la Convención Interamericana para Prevenir, Erradicar y Sancionar la Violencia contra la Mujer, Convención "Belém do Pará", de modo tal que nuestra legislación actual reconoce la violencia no solo dentro del ámbito doméstico (interno), sino también en el ámbito público, sumado a la violencia por razones de género, como una respuesta a las desigualdades estructurales sociales hacia las mujeres.

Desde el enfoque penal, hay que dejar constancia que con la ley anterior los actos de violencia contra las mujeres que se realizaban fuera de ámbito doméstico no constituían delito, quedando en impunidad.

No menos importante en el Capítulo III se contemplan los derechos de las mujeres y del grupo familiar, resaltando entre ellos el derecho a una vida libre de violencia, derecho a la

27 Artículo $4^{\circ}$.- Ámbito de aplicación de la Ley.- Las disposiciones de la presente ley se aplican a todos los tipos de violencia contra las mujeres por su condición de tales y contra los integrantes del grupo familiar.

28 Artículo $5^{\circ}$.- Definición de violencia contra las mujeres.- La violencia contra las mujeres es cualquier acción o conducta que les causa muerte, daño o sufrimiento físico, sexual o psicológico por su condición de tales, tanto en el ámbito público como el privado.

Se entiende por violencia contra las mujeres:

a. La que tenga lugar dentro de la familia o unidad doméstica o en cualquier otra relación interpersonal ya sea que el agresor comparta o haya compartido el mismo domicilio que la mujer. Comprende entre otros violación, maltrato físico o psicológico y abuso sexual.

b. La que tenga lugar en la comunidad. Sea perpetrada por cualquier persona y comprende, entre otros, violación, abuso sexual, tortura, trata de personas, prostitución forzada, secuestro y acoso sexual en el lugar de trabajo, así como en instituciones educativas, establecimientos de salud o cualquier otro lugar.

c. La que sea perpetrada o tolerada por los agentes del Estado, donde quiera que ocurra.

29 Articulo 6.- Definición de violencia contra los integrantes del grupo familiar.- La violencia contra cualquier integrante del grupo familiar es cualquier acción o conducta que le causa muerte, daño o sufrimiento físico, sexual o psicológico y que se produce en el contexto de una relación de responsabilidad, confianza o poder, de parte de un integrante a otro del grupo familiar.

Se tiene especial consideración con las niñas, niños, adolescentes, adultos mayores y personas con discapacidad. 
asistencia y la protección, destacando el derecho al acceso a la información, asistencia jurídica y defensa pública, promoción, prevención y atención de salud y por último la atención social. Así mismo destaca los derechos laborales y los derechos en el campo de la educación.

Debe precisarse que el Código Procesal Penal establece que la víctima debe ser informada de sus derechos cuando interponga la denuncia o en su primera intervención en la causa. Debemos entender que quiere decir que a la víctima se le debe brindar toda la información que necesita desde el primer momento que entra en contacto con la autoridad. Este aspecto resulta esencial si consideramos que el primer aspecto que abarca el derecho a una información veraz para la víctima es el relativo a que se le informe de los derechos que tiene al interior del proceso, pues de muy poco sirve que tenga tales derechos si no sabe que los tiene, ni cuáles son las garantías que existen para proteger tales derechos. ${ }^{30}$

Por ello consideramos muy acertado lo expresado en la norma destacando el derecho al acceso a la información, ya que la víctima, en ausencia de un abogado, se encontrará asistida por el órgano jurisdiccional.

\section{TíTULO II: Proceso de Tutela Frente a la Violencia contra las Mujeres y los Integrantes del Grupo Familiar:}

Consideramos acertada la competencia de los juzgados de familia ${ }^{31}$ en las denuncias por actos de violencia contra las mujeres o contra los integrantes de un grupo familiar; sin embargo, lo no acertado es el proceso, que a todas luces en su indefensión en la aplicación genera una profunda desprotección a las víctimas de violencia contra las mujeres o contra los integrantes de un grupo familiar.

Con respeto a la denuncia ${ }^{32}$ por actos de violencia contra las mujeres o contra los integrantes de un grupo familiar consideramos acertada la norma, ya que no requiere a la víctima de violencia contra las mujeres o contra los integrantes de un grupo familiar presentar su denuncia

30 Elky Villegas Paiva, El agraviado y la reparación civil en el nuevo Código Procesal Penal..., 23.

31 Artículo 14.- Competencia de los Juzgados de Familia.- Son competentes los juzgados de familia o los que cumplan sus funciones para conocer las denuncias por actos de violencia contra las mujeres o contra los integrantes de un grupo familiar.

32 Artículo $15^{\circ}$.- Denuncia.- La denuncia puede presentarse por escrito o verbalmente. Cuando se trata de una denuncia verbal, se levanta un acta sin otra exigencia que la de suministrar una sucinta relación de los hechos.

La denuncia puede ser interpuesta por la persona perjudicada o por cualquier otra en su favor, sin necesidad de tener su representación. También puede interponer la defensoría del pueblo. No se requiere firma del letrado, tasa o alguna otra formalidad.

Sin perjuicio de lo expuesto, los profesionales de la salud y educación deben denunciar los casos de violencia contra la mujer o los integrantes del grupo familiar que conozcan en el desempeño de su actividad.

Cuando la Policía Nacional de Perú conozca de casos de violencia contra la mujer o los integrantes del grupo familiar, en cualquiera de sus comisarias del ámbito nacional debe poner los hechos en conocimiento de los juzgados de familia o los que cumplan sus funciones dentro de las veinticuatro horas de conocido el hecho, resumiendo el atestado que resuma lo actuado. 
por escrito y con firma del letrado a fin de solicitar la tutela jurisdiccional efectiva. Esto es de gran ayuda, ya que muchas veces la víctima de violencia de género depende económicamente de su agresor, consecuentemente no cuenta con recursos económicos para ser asistida por un abogado. Para que la denuncia sea eficaz dice la norma se debe levantar un acta sin otra exigencia que la de suministrar una sucinta relación de los hechos.

Lo que sí consideramos que el legislador no ha tomado en cuenta es lo siguiente: ¿qué sucede cuando la denuncia es calumniosa amparándose la denunciante en su condición de mujer?, o ¿qué sucedería si la denunciante induce a un menor de edad a denunciar a su padre por un supuesto maltrato físico, con el único objetivo de obtener una medida cautelar ordenada por el juez de familia "de Retiro del Agresor del domicilio"? Estas imprecisiones deben ser reguladas por el Reglamento de la Ley No 30364 "Ley para Prevenir, Sancionar y Erradicar la Violencia contra las Mujeres y los Integrantes del Grupo Familiar”. Por ello consideramos que a la par de que se acepte una denuncia verbal, también se exija a la denunciante que firme declaración jurada de verdad de los hechos que narra en su denuncia, bajo apercibimiento de las acciones penales correspondientes.

Esto en la medida que el artículo 16 de la norma en comento establece plazos muy cortos en desarrollo del proceso, ${ }^{33}$ ya que prácticamente conmina al juez a resolver y dictar las medidas cautelares correspondientes en un corto plazo de 72 horas; plazo que es muy corto para que el juez de familia pueda valorar la prueba, pudiendo el magistrado caer en error y ocasionar un grave perjuicio al denunciado; convirtiéndose este último en la víctima del sistema. Más aún que en un corto plazo sea puesto en conocimiento de la Fiscalía Penal para el inicio del proceso penal.

Consideramos impreciso también y poco acertado que la declaración de la víctima y entrevista única sea constituida la calidad de prueba constituida, en la medida que el legislador no ha tomado en cuenta qué sucedería si la declaración de la víctima es de mala fe, qué sucede si la entrevista del menor fue inducida por su progenitor y mintió para perjudicar al denunciado. Aquí se estaría atentando contra el principio constitucional del derecho a la defensa y el debido proceso.

33 Artículo $16^{\circ}$.- Proceso.- En el plazo máximo de setenta y dos horas siguientes a la interposición de la denuncia, el Juzgado de Familia o su equivalente procede a evaluar el caso y resuelve en audiencia oral la emisión de las medidas de protección requeridas que sean necesarias. Así mismo de oficio o a solicitud de la víctima, en la audiencia oral se pronuncia sobre medidas cautelares que resguardan pretensiones de alimentos, regímenes de visita, tenencia, suspensión o extinción de la patria potestad, liquidación de régimen patrimonial y otros aspectos conexos que sean necesarios para garantizar el bienestar de las víctimas.

Analizados los actuados, el Juzgado de Familia, o su equivalente, procede a remitir el caso a la Fiscalía Penal para el inicio del proceso penal, promulgado por el Decreto Legislativo 957. 


\section{CAPÍTULO II.- Medidas de Protección}

Las medidas de protección ${ }^{34}$ las consideramos muy acertadas; sin embargo, consideramos que no deben ser inmediatas en su ejecución hasta que exista una verdadera valoración de la prueba, ya que podría aprovecharse en su aplicación y perjudicar el normal desarrollo del proceso.

Consideramos no acertada la protección a la víctima ${ }^{35}$ en las actuaciones de investigación, ya que contempla la prohibición de la confrontación entre la víctima y el agresor; eso deja en indefensión al denunciado, violándose el derecho a la tutela jurisdiccional efectiva, el cual, según García Morillo, ${ }^{36}$ es un derecho de todas las personas a tener acceso al sistema judicial y a obtener del mismo una resolución fundada en derecho y, por tanto, motivada, que pueda ser de inadmisión cuando concurre una causa legalmente prevista. A ello hay que añadir el derecho a no sufrir indefensión, es decir, a poder ejercer en el proceso, en apoyo de la propia posición, todas las facultades legalmente reconocidas.

El derecho a la tutela jurisdiccional efectiva, reconocido en el artículo 139 inciso 3 de la Constitución Política, implica que cuando una persona (en este caso la víctima de violencia de genero) pretenda la defensa de sus derechos o intereses legítimos, ella tenga la posibilidad de ser atendida por un órgano jurisdiccional, mediante un proceso dotado de un conjunto de garantías mínimas y efectivas para la protección de tales derechos, de lo contrario ya no sería tutela jurisdiccional efectiva. En ese sentido, la tutela jurisdiccional efectiva comprende una serie de derechos entre los que destacan el acceso a la justicia, ${ }^{37}$ es decir, el derecho de cualquier persona de promover la actividad jurisdiccional del Estado, sin

34 Artículo 22.- Medidas de protección.- Entre las medidas de protección que pueden dictarse en los procesos por actos de violencia contra las mujeres y los integrantes de un grupo familiar se encuentran, entre otros, los siguientes:

1. Retiro del agresor del domicilio.

2. Impedimento de acercamiento o proximidad a la víctima en cualquier forma a la distancia que la autoridad judicial determine.

3. Prohibición de comunicación con la víctima vía epistolar, teléfono, electrónica, asimismo vía chat, redes sociales, red institucional, internet $\mathrm{u}$ otras redes o formas de comunicación.

4. Prohibición del derecho de tenencia y porte de armas para el agresor, debiéndose notificar a la Superintendencia Nacional de Control de Servicios de Seguridad, Armas, Municiones y Explosivos de Uso Civil para que proceda a dejar sin efecto la licencia de posesión y uso, y para que se incauten las armas que están en posesión de personas respecto de las cuales se haya dictado la medida de protección.

5. Inventario sobre sus bienes.

6. Cualquier otra requerida para la protección de la integridad personal y la vida de sus víctimas o familiares.

35 Artículo $25^{\circ}$.- Protección de las víctimas en las actuaciones de investigación-. En el trámite de los procesos por violencia contra las mujeres y los integrantes del grupo familiar están prohibidas la confrontación y la conciliación entre la víctima y el agresor. La reconstrucción de los hechos debe practicarse sin la presencia de aquella, salvo que la víctima mayor de catorce años de edad lo solicite, sin perjuicio de lo dispuesto en el artículo 194, inciso 3 del Código Procesal Penal, promulgado por el Decreto Legislativo 957.

36 Joaquín García Morillo, Derecho Constitucional, vol. 1, tercera edición (Valencia: Tirant lo Blanch, 1997), 324.

37 Véase la STC Exp. Nº 04080-2004-AC/TC, f j. 14. 
que se le obstruya, impida o disuada irrazonablemente, y el derecho a la efectividad de las resoluciones judiciales. ${ }^{38}$

El citado derecho no se agota en el libre acceso a ese recurso, es decir, en la mera posibilidad de acceder al tribunal, sino que requiere que el órgano interviniente produzca y exponga una conclusión razonada sobre los méritos del reclamo (derecho a la debida motivación), que establezca la procedencia o improcedencia de la pretensión jurídica que le da origen, y también que se garantice el cumplimiento, por las autoridades competentes, de toda decisión en que se haya estimado procedente el recurso. El recurso debe ser efectivo, por lo que no alcanza su mera existencia formal, ${ }^{39}$ pues la efectividad exige que sea adecuado (que la función del recurso que sea en el sistema de Derecho interno sea idónea para proteger la situación jurídica infringida) y eficaz (capaz de producir el resultado para el que ha sido concebido. $^{40}$

Por ello consideramos que el derecho a la tutela jurisdiccional efectiva no es solo un derecho de la denunciante, sino también del denunciado. En un proceso de tan solo 72 horas no se puede valorar de manera eficaz la prueba.

Los juzgados de familia en nuestro país son insuficientes para resolver los conflictos que se contraen en familia. Los problemas que más aquejan son de violencia familiar y alimentos, que muchas veces no tienen resultados inmediatos; y de ser inmediatas muchas veces no son acertados, violándose el principio del debido proceso.

Es necesaria la creación de juzgados especializados en violencia contra la mujer, como sucede en otros países.

Consideramos que el problema radica en el plazo máximo de 72 horas que tiene el juzgador para evaluar el caso, plazo mínimo e insuficiente para que el juzgador de manera motivada pueda pronunciarse sobre las medidas de protección de manera eficaz.

38 Véase la STC Exp. Nº15-200Irrc, fojas. 16.

39 En este sentido, la Corte IDH ha señalado que "no basta con la existencia formal de los recursos, sino que esos deben ser eficaces, es decir, deben dar resultados o respuestas a las violaciones de derechos contemplados en la Convención. Este tribunal ha señalado que no pueden considerarse efectivos aquellos recursos que, por las condiciones generales del país o incluso por las circunstancias particulares de un caso dado, resulten ilusorios. Ello puede ocurrir, por ejemplo, cuando su inutilidad haya quedado demostrada por la práctica, porque el órgano jurisdiccional carezca de independencia necesaria para decidir con imparcialidad o porque falten los medios para ejecutar sus decisiones; por cualquier otra situación que configure un cuadro de denegación de justicia, como sucede cuando se incurre en retardo injustificado" (Corte IDH. Caso Las Palmeras vs. Colombia. Sentencia de fondo del 6 de diciembre de 2001, párr. 58).

40 José Caferata Nores, Derecho de la víctima a la tutela judicial efectiva (Buenos Aires: Astrea, 2004), 2. 
TÍTULO III: Prevención de la Violencia, Atención y Recuperación de Victimas y Reeducación de Personas Agresoras.

Consideramos acertados los servicios de promoción, prevención y recuperación de víctimas de violencia ${ }^{41}$ específicamente con la creación de servicios de atención y prevención contra la violencia; sin embargo consideramos no acertado que dichos servicios de promoción, prevención y recuperación de víctimas de violencia se encuentren a cargo de los Gobiernos locales, regionales y del Ministerio de la Mujer y Poblaciones Vulnerables, ya que estos últimos a la fecha no cumplen sus objetivos por la excesiva carga administrativa. Debemos recordar que en nuestro país existe una protección normativa en la Ley $\mathrm{N}^{\circ} 28236^{42}$ que crea hogares de refugio temporal para las víctimas de violencia familiar, que sin embargo no es eficaz, por la falta de presupuesto para cumplir sus fines, y sobre todo porque dejaba en desprotección a la mujer víctima del maltrato.

Otro aspecto importante y acertado en la ley en comento es el tratamiento penitenciario para la reinserción social de las personas agresoras privadas de libertad. ${ }^{43}$ Sin embargo, debemos tener presente que aún queda la tarea de tratamiento penitenciario para reinserción social de las personas de delitos comunes.

\section{TÍTULO IV.- Sistema Nacional para la Prevención, Sanción y Erradicación de la Violencia contra las Mujeres y los Integrantes del Grupo Familiar.}

Nos causa admiración la constitución de una Comisión Multisectorial de Alto Nivel, ${ }^{44}$ la

41 Artículo 27.- Servicios de promoción, prevención y recuperación de víctimas de violencia. La protección de las mujeres y de los integrantes del grupo familiar contra actos de violencia es de interés público. El Estado es responsable de promover la prevención contra dichos actos y la recuperación de las víctimas.

Es Política del Estado la creación de servicios de atención y prevención contra la violencia.

La creación y gestión de los hogares de refugio temporal, programa dirigido a varones para prevenir conductas violentas y otros servicios de protección a favor de las víctimas de violencia contra la mujer e integrantes del grupo familiar estarán a cargo de los gobiernos locales, regionales y del Ministerio de la Mujer y Poblaciones Vulnerables. Es función de dicho sector promover, coordinar y articular la implementación de dichos servicios en cada localidad.

42 Ley N 28236 que crea hogares de refugio temporal para las víctimas de violencia familiar, de fecha de publicación del 29 de mayo del 2004.

43 Artículo 31.- Tratamiento penitenciario para la reinserción social de las personas agresoras privadas de libertad.- El instituto Nacional Penitenciario incorpora el eje de prevención de la violencia contra las mujeres y los integrantes del grupo familia dentro de los distintos programas de tratamiento penitenciario dirigidos a la población penal.

El condenado a pena privativa de libertad efectiva por delitos vinculados a la violencia contra las mujeres y los integrantes del grupo familiar, previa evaluación, debe seguir un tratamiento de reducción de carácter multidisciplinario y diferenciado, teniendo en cuenta los enfoques consignados en esta ley a fin de solicitar su reinserción en la social. El cumplimiento del tratamiento es un requisito obligatorio para el otorgamiento de beneficios penitenciarios de indulto y de la conmutación de la pena a los que hubiere lugar, conforme al marco legal vigente, los que no pueden ser concedidos sin el correspondiente informe psicológico y social que se pronuncie sobre la evolución del tratamiento diferenciado.

El Ministerio de la Mujer y Poblaciones Vulnerables presta asistencia técnica para el diseño de programas de reeducación.

44 Artículo 35․- Comisión Multisectorial de Alto Nivel.- Constitúyase la Comisión Multisectorial de Alto Nivel con la finalidad de dirigir el Sistema Nacional para la Prevención, Sanción y Erradicación de la Violencia contra la Mujer y los Integrantes de un grupo familiar y formular los lineamientos y la evaluación de lo establecido en la presente norma. 
misma que estará presidida por el titular o el representante de la alta dirección del Ministerio de la Mujer y Poblaciones Vulnerables e integrada por los titulares o los representantes de la más alta dirección de las instituciones que se determinen en el reglamento de la presente ley; que sin embargo al cierre del presente artículo solo ha quedado en creación de la mencionada comisión.

Preocupa esta falta de articulación por parte del Estado, lo cual nos indica que no es una prioridad de política nacional, pues no se ha destinado una partida presupuestaria para esta ley. Queda preguntarse si se va a implementar o no, y si la respuesta es negativa, qué sucederá con la atención de los casos de violencia contra las mujeres.

\section{DISPOSICIONES COMPLEMENTARIAS FINALES:}

Con respecto a la reglamentación ${ }^{45}$ de la Ley N³0364, refiere la norma en su disposición Primera, que el reglamento de la ley será expedida en un plazo no mayor a noventa días; sin embargo, a la fecha de la publicación del presente artículo no ha sido publicada su reglamentación. Contrariamente a ello, se ha publicado, con fecha 12 de febrero del 2016, la Resolución Suprema que crea la Comisión Multisectorial, de naturaleza temporal, encargada de elaborar el informe que contenga la propuesta de la Ley $N^{\circ} 30364$, Ley para Prevenir, Sancionar y Erradicar la Violencia Contra las Mujeres y los Integrantes del Grupo Familiar.

Ello quiere decir que a la fecha no existe un reglamento de la Ley $\mathrm{N}^{\circ} 30364$, lo que causa un perjuicio a la mujer víctima de maltrato en su condición de género, ya que los jueces a cargo de la administración de justicia resuelven el proceso a su entender en el plazo sumarísimo de 72 horas, muchas veces violando el debido proceso y la tutela jurisdiccional efectiva.

En mi condición de investigador de la victimología, expedida dicha norma, la consideré acertada y efectiva; sin embargo, haciendo una revisión exhaustiva, casi todas las ventajas que nos ofrece la norma ya se encontraban reguladas por otras normas que no han sido eficaces

La comisión está presidida por el titular o el representante de la alta dirección del Ministerio de la Mujer y Poblaciones Vulnerables integrada por los titulares o los representantes de la alta dirección de las instituciones que se determinen en el Reglamento de la presente Ley.

El Ministerio de la Mujer y Poblaciones Vulnerables es el ente rector en materia de prevención, protección y atención de la violencia contra las mujeres y los integrantes de un grupo familiar y el responsable de la coordinación, articulación y vigilancia de la aplicación efectiva y el cumplimiento de la presente ley.

La Dirección General contra la Violencia de Género del citado ministerio se constituye como Secretaría Técnica de la Comisión, la cual convoca a especialistas de diferentes sectores y representantes sectoriales y representantes de la sociedad civil con la finalidad de constituir un grupo de trabajo nacional.

El reglamento de esta ley regula el funcionamiento de la Comisión.

45 PRIMERA. Reglamentación.- El reglamento de la presente ley se expide por el poder Ejecutivo en un plazo no mayor a noventa días calendario desde su entrada en vigencia. Para tal efecto, se convoca a una comisión conformada por el Ministerio de Justicia y Derechos Humanos, el Ministerio de la Mujer y Poblaciones Vulnerables, el Ministerio del Interior, el Poder Judicial y el Ministerio Público. 
en su aplicación, en muchos casos por falta de presupuesto en su implementación. Esperemos pacientemente la reglamentación para el cumplimiento de sus fines de la Ley $\mathrm{N}^{\circ} 30364$ "Ley para Prevenir, Sancionar y Erradicar la Violencia contra las Mujeres y los Integrantes del Grupo Familiar", que esperemos tenga un verdadero amparo normativo en la violencia contra las mujeres y los integrantes del grupo familiar.

Sin embargo, lo que sí me parece una innovación es el plazo del proceso sumarísimo, norma que a todas luces atenta con el principio del debido proceso, ya que obliga al juzgador a valorar la prueba que obre en el expediente en 72 horas; y además de ello, obliga al juzgador a dictar medidas de protección. El juzgador se encuentra obligado a pronunciarse con las pruebas que obran en autos, así sean insuficientes, ya que el magistrado tiene que dar cumplimiento a la norma y no caer en la omisión, rehusamiento o demora de actos funcionales, previstos y penados en el artículo $377^{46}$ del Código Penal.

Desde la entrada en vigencia la Ley No 30364 "Ley para Prevenir, Sancionar y Erradicar la Violencia contra las Mujeres y los Integrantes del Grupo Familiar" se han suscitado muchos problemas, dejando en indefensión a la verdadera víctima de violencia en su condición de género. Recuérdese que cada expediente que ingresa al Poder Judicial a exigir la tutela jurisdiccional efectiva suma la carga procesal del mismo; por ello sugerimos que el Estado debe reglamentar a la brevedad posible la norma en comento, y crear un Juzgado Especializado de Familia, subespecialidad de violencia contra las mujeres y los integrantes del grupo familiar.

Un aspecto adicional a mencionar es que la norma en comento define en el artículo 8 los cuatro tipos de violencia contra las mujeres e integrantes del grupo familiar: física, psicológica, sexual y económica, los cuales se adaptan a los estándares internacionales en materia de derechos humanos. Así, podemos mencionar que reconoce la violencia patrimonial hacia las mujeres.

\section{CONCLUSIONES}

1. La violencia depende de factores biológicos, psicopatológicos, genéticos, ambientales y además socioculturales como el desempleo, pobreza, crisis de valores, y la educación recibida desde la infancia hasta el periodo de adultez, los cuales constituyen distractores al momento de comprender en todas sus dimensiones las diversas manifestaciones de la no violencia. ${ }^{47}$

46 Artículo 377.- Omisión, rehusamiento o demora de actos funcionales.- El funcionario público que ilegalmente omite, rehúsa o retarda algún acto de su cargo será reprimido con pena privativa de libertad no mayor de dos años y con treinta a sesenta días-multa.

Cuando la omisión, rehusamiento o demora de actos funcionales esté referido a una solicitud de garantías personales o caso de violencia familiar, la pena será privativa de la libertad no menor de dos años ni mayor de cinco años.

47 Citado por "Estudios de Derecho. Un acercamiento teórico a la mujer víctima-victimaria”..., 237. 
Por ello es importante que el Estado otorgue las garantías mínimas para prevenir la violencia contra las mujeres y los integrantes del grupo familiar.

2. De acuerdo al planteamiento de Eugenio Zafaroni, la criminalidad femenina es un problema de las estructuras sociales, políticas, económicas y culturales de un país, y por eso el tratamiento de los delincuentes debe efectuarse de acuerdo a las necesidades de la población y sustentarse en la idea de control y justicia social de un Derecho Penal más preventivo que sancionativo. La política criminal debe ir en búsqueda del diseño de instrumentos con criterios jurídico-penales que persigan la defensa social de los individuos, plantear soluciones a los conflictos, garantizar el respeto por la libertad, el buen nombre y la honra de las personas vinculadas penalmente a procesos; y reconceptualizar la pena, delito, victimización, justicia, marginalización y la discriminación. ${ }^{48}$ Coincidimos en afirmar que la solución al problema planteado no está en expedir normas sancionatorias, sino que debemos enfocarnos en dar solución al problema otorgando normas preventivas que puedan ejecutarse en nuestro país.

3. Consideramos importante que en el reglamento a expedir se superen las omisiones advertidas en la norma, entendiendo que el marco normativo materia de análisis resulta ser un hibrido jurídico respecto a la contemplación de instituciones jurídicas provenientes del Derecho Civil, Derecho de Familia, Código del Niño y del Adolescente, Ley del Adulto Mayor, y las disposiciones administrativas vigentes referidas a la protección de los derechos de las poblaciones vulnerables. Es necesaria la creación de un sistema donde el operador jurisdiccional (como en el caso de los juzgados de tránsito) cuente con la especialización en materia sustantiva, procesal y ejecutiva, en los cuerpos normativos antes referidos para que se aplique una correcta administración de justicia. Esto es, se hace necesario el establecimiento de un proceso especial como operadores jurisdiccionales especializados y juzgados de la materia, lo que evitaría la dilación innecesaria de admitir la denuncia en el juzgado de familia, para que este solo otorgue medidas cautelares y que para encontrar la futura responsabilidad del denunciado tenga que remitirlo a una fiscalía especializada en lo penal, y este a su vez al juzgado penal.

4. La norma en comento, conforme ha sido delineada para la mayoría de los casos de índole penal, ha convertido al juzgado de familia en una mesa de partes de denuncias por violencia familiar y órgano resolutivo de medidas cautelares, no otorgándole competencia para que resuelva sobre el fondo del asunto en casos penales, los que son derivados al juez especializado en lo penal, deviniendo esto en una acción innecesaria, perjudicando a la víctima de violencia por género.

Por último, estando a la celeridad del proceso, este resultaría, en algunos casos por la mala fe del denunciante y/o el supuesto agraviado, en un proceso violatorio a los derechos

48 “Estudios de Derecho. Un acercamiento teórico a la mujer víctima-victimaria”..., 248. 
fundamentales del denunciado, quien ve recortado su derecho a la defensa con las garantías de un debido proceso ante la poca o escasa actividad probatoria, por cuanto la mera sindicación de la supuesta víctima se está constituyendo en prueba preconstituida, resultando contradictoria a los lineamientos desarrollados por el Poder Judicial en materia penal referida a los casos en que basta la mera sindicación para encontrar responsable al denunciado. ${ }^{49}$

5. Para concluir el presente artículo consideramos de manera emergente la expedición del Reglamento de la Ley No 30364 "Ley para Prevenir, Sancionar y Erradicar la violencia contra las Mujeres y los Integrantes del Grupo Familiar".

6. Debe mencionarse que el Ministerio de la Mujer y Poblaciones Vulnerables es el encargado de la dirección, asesoría y fiscalización de los diferentes sectores del Estado sobre los temas de violencia contra las mujeres e integrantes del grupo familiar; sin embargo, sin una articulación debida con los demás entes encargados de su cumplimiento, la norma no va a resultar eficaz.

\section{REFERENCIAS}

- Caferata Nores, José. Derecho de la víctima a la tutela judicial efectiva. Buenos Aires: Astrea, 2004.

- "Estudios de Derecho. Un acercamiento teórico a la mujer víctima-victimaría". Proyecto de investigación publicado por la Universidad de Antioquia, 155, volumen LXX, segunda época (junio de 2013).

- García Morillo, Joaquín. Derecho Constitucional. Vol. 1. Tercera edición. Valencia: Tirant lo Blanch, 1997.

- Gorjon Barranco, María Concepción. La tipificación del género en el ámbito penal. España: IUSTEL, Universidad de Salamanca, 2012.

- Neuman, Elías. El rol de la víctima en los delitos convencionales. Buenos Aires: Universidad de Buenos Aires, 1984.

- Roel Alva, Luis Andrés. "El derecho a la reparación económica del Programa Integral de Reparación del Estado". Gaceta Constitucional, 69 (setiembre de 2013).

49 Véase al acuerdo plenario $\mathrm{N}^{\circ} 2-2005 / \mathrm{CJ}-116$ de fecha 30 de setiembre del 2005. 
- Rosillo Sánchez, Omar Levi. "La víctima y el testigo en el Código Procesal Penal de 2004”. Revista de Actualidad Jurídica, 197 (2010).

- Villegas Paiva, Elky. El agraviado y la reparación civil en el nuevo Código Procesal Penal. Primera edición. Lima: Editorial Gaceta Jurídica S.A. 


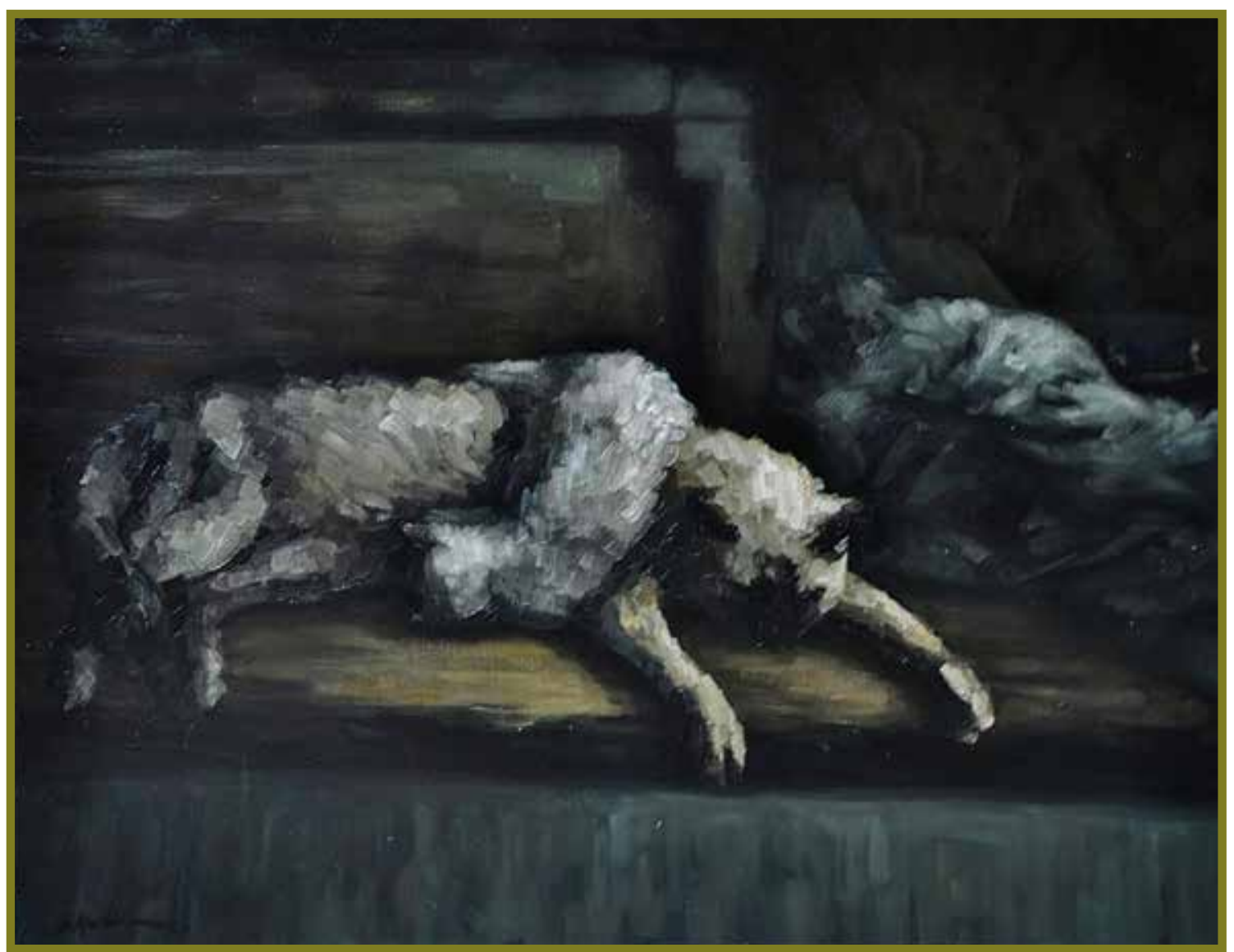

Maternidad $(70 \mathrm{~cm}$ x $90 \mathrm{~cm})$. Diego Alcalde Taboada. 